DOI:10.2478/rrlm-2018-0025

\title{
Association between MDR1 gene polymorphism and clinical course of pediatric pulmonary arterial hypertension
}

\author{
Iolanda Muntean $^{1 \#}$, Carmen Şuteu ${ }^{1 \#}$, Rodica Togănel ${ }^{1 *}$, Claudia Bănescu ${ }^{2}$ \\ 1. University of Medicine and Pharmacy Tîrgu Mureș, Institute of Cardiovascular Disease and \\ Transplantation, Clinic of Pediatric Cardiology, Tîrgu Mureș, Romania \\ 2. University of Medicine and Pharmacy Tîrgu Mureș, Emergency County Hospital, Genetic \\ Department, Tîrgu Mureș, Romania
}

\begin{abstract}
Pulmonary arterial hypertension (PAH) is a progressive disease with a complex pathogenesis. The polymorphism of the gene of multidrug resistance-1 (MDR1) has been associated with many diseases including PAH.

Objective. In this study we aimed to investigate the relevance of the MDR1 polymorphism to pediatric PAH clinical course.

Methods. A total of 40 pediatric patients with PAH (secondary to congenital heart defects or idiopathic) and 40 control subjects were enrolled. Patients with PAH were divided into 2 groups, according to their evolution: 28 patients who remained clinically stable at 12-months (non-worsening group) and 12 patients who presented clinical worsening at 12-months (worsening group). Genomic DNA was genotyped for MDR1 gene polymorphisms as follows: C1236T, G2677T and C3435T.
\end{abstract}

Results. There were no significant differences between PAH children groups (clinical worsening and non-worsening) nor between PAH children and controls in terms of frequency distribution of the three studied genotypes or alleles.

Conclusions. The MDR1 polymorphism could not be correlated with the clinical evolution of pediatric PAH patients in our study.

Keywords: MDR1 gene polymorphism, pulmonary arterial hypertension, congenital heart defects

Received: $6^{\text {th }}$ May 2018; Accepted: $5^{\text {th }}$ July 2018; Published: $10^{\text {th }}$ July 2018

\section{Introduction}

Pulmonary arterial hypertension (PAH) is a hemodynamic and pathophysiological condition with multiple etiologies characterized by chron- ic and progressive remodelling of small pulmonary arteries, resulting in increased pulmonary vascular resistance (PVR) (1). Evidence suggests that inflammation, nitrogen oxides and oxidative

*Corresponding author: Rodica Toganel, University of Medicine and Pharmacy Tîrgu Mureș, Institute of Cardiovascular Disease and Transplantation, Tirgu Mures, Romania. E-mail: rodicatoganel@yahoo.com

\# IM and CŞ contributed equally to this work 
stress contribute to the development and progression of lesions in the pulmonary vasculature $(2,3)$. The reactive oxygen species (ROS) are an important mediator of vascular tonus, their excess generation being involved in the pathogenesis of PAH $(4,5)$. Despite recent therapeutic advances in PAH which targets the three major pathophysiological pathways: the endothelin pathway, the prostacyclin pathway and the nitric oxide pathway, the evolution of many patients with PAH is progressive $(1,6-8)$.

The role of genetics in PAH, both the risk of developing the disease and the progression of pulmonary vascular lesions, has been proven (9-14). The human multidrug resistance gene (MDR1) (or ABCB1) encodes an integrated membrane protein, P-glycoprotein (Pgp), which plays an important role in the bioavailability of some drug agents and also in the protection of cells against toxic substances and metabolites by acting ATP-dependent cellular efflux mechanism (15). P-glycoprotein is expressed in the epithelial cells of different organs, including the lungs, where it facilitates transmembrane intracellular transport of various toxins, decreasing the intracellular concentration of toxic compounds $(12,16)$. MDR1 polymorphism is associated with the decrease synthesis and function alteration of P-gp. From more than 50 single nucleotide MDR1 polymorphisms, MDR C3435T, MDR C1236T and MDR G2677T polymorphisms are the most extensively studied (17-22).

MDR1 polymorphism could not be associated with the effectiveness of pulmonary vasodilator therapy because endothelin receptor antagonists and phosphodiesterase type 5 inhibitors are not substrate for P-gp. However, the MDR1 polymorphism, lowering expression of the P-gp in the pulmonary tissue, may be involved in the progression of PAH by affecting cellular protection against the deleterious action of ROS (23). The aim of our study is to determine the rele- vance of MDR1 polymorphism in the pediatric PAH clinical course.

\section{Material and Methods}

This is a prospective case-control study in which we assess three polymorphisms in MDR1 gene: G2677T, C1236T and C3435T in PAH patients and in age- and sex-matched healthy children. The study protocol was approved by the local Ethics Committee of the University of Medicine and Pharmacy of Tirgu Mures. A written informed consent was obtained from the parents of all the children included in study.

Study population. A total of 40 consecutive pediatric patients with PAH (median age of 9.75 \pm 4.38 years), treated in the largest pediatric $\mathrm{PAH}$ Centre in Romania, were evaluated in this prospective longitudinal, non-interventional study. PAH was defined in accordance with 2015 ESC/ ERS Guidelines as an increase in mean pulmonary arterial pressure $\geq 25 \mathrm{mmHg}$ at rest as assessed by right heart catheterization, a pulmonary artery wedge pressure (PAWP) $\leq 15 \mathrm{mmHg}$, and a PVR $>3$ Wood units in the absence of any other causes of precapillary PAH (24). Exclusion criteria: Patients older than 18 years and those with pulmonary hypertension due to left heart disease.

PAH etiology was secondary to congenital heart defects (PAH-CHD) in 36 children (90\%) and idiopathic (IPAH) in 4 children (10\%). Echocardiography was performed in all children with an iE33 (Philips Medical Systems, Best, Netherlands) ultrasound machine. Patients underwent a complete physical examination, assessment of WHO functional class (WHO FC) and assessment of exercise capacity, estimated with the 6-minute walking test (6MWT) in children $\geq 5$ years. The $6 \mathrm{MWT}$ was performed using standard protocol as American Thoracic Society (ATS) guideline (25). Patients were treated with specific vasodilator therapy in accordance with the current guidelines recommendation (24). 
Further, the patients were divided into 2 groups, according to their evolution after 12 months of follow-up: non-worsening group, consists of patients who remained clinically stable at 12-months $(n=28.70 \%)$ and worsening group, consists of patients who presented clinical worsening at 12-months due to progressive RV failure $(n=12.30 \%)$. Clinical worsening was defined as an increase in WHO FC with at least one class.

Forty age- and sex-matched healthy children, with no heart defects or pulmonary hypertension referred to the pediatricians for routine evaluation or flu were included in the study as controls (Table 1).

\section{Genotyping}

Genotyping was performed in all $\mathrm{PAH}$ patients and controls included in the study. Genomic DNA, isolated from fresh blood obtained from children included in the present research was genotyped for MDR1 (or ABCB1) gene polymorphisms as follows: C1236T, G2677T and C3435T. The genotypes of the investigated MDR1 gene, namely C1236T, G2677T and C3435T gene polymorphisms were established by using the polymerase chain reaction-restriction fragment length polymorphism (PCRRFLP) analysis as previously described by Dong et al and corresponding FastDigest restriction enzyme (namely FastDigest EcoO109I, FastDigest BshNI, FastDigest MboI) supplied by ThermoFisher Scientific. The PCR conditions were similar to those reported previously $(26,27)$

\section{Statistical analysis}

Statistical analysis was performed by Graph Pad InStat software (version 3.0). package program. All data were given as mean \pm standard deviation (SD). Student's t-test was used to compare the parametric variables. Chi-square test (or Fisher exact test when appropriate) was used for the comparison of the frequency distribution of genotypes and alleles between PAH patients and controls and also between worsening and non-worsening PAH groups. $P$ values $<0.05$ were considered as statistically significant.

\section{Results}

\section{MDR1 SNPs genotypes and alleles in PAH} children and control group

Table 2 summarizes the genotype distributions and allele frequencies of the MDR1 C1236T, MDR1 G2677T and MDR1 C3435T polymorphisms in PAH group and control children. There were no significant differences in frequency distribution of the three studied genotypes or alleles between PAH patients and control children.

Table 1. Demographic data in patients with PAH and healthy controls

\begin{tabular}{lccc}
\hline & PAH $(\mathbf{n}=\mathbf{4 0})$ & Control group $(\mathbf{n}=\mathbf{4 0})$ & P value \\
\hline Age (y) & $9.75 \pm 4.38$ & $9.49 \pm 2.93$ & 0.768 \\
\hline Male (\%) & $18(45 \%)$ & $16(40 \%)$ & 0.821 \\
\hline PAH type & & & NA \\
\hline idiopathic & $4(10 \%)$ & NA & NA \\
\hline CHD & $36(90 \%)$ & NA & NA \\
\hline Medication no (\%) & & NA & NA \\
\hline Sildenafil & 12 & NA & NA \\
\hline Bosentan & 18 & NA & \\
\hline Combination & 10 & &
\end{tabular}

Data are presented as means \pm SD or no (\%)

$\mathrm{CHD}$, congenital heart defects; $\mathrm{PAH}$, pulmonary arterial hypertension; y, year 
Table 2. Distribution of different genotypes and allele distribution in PAH group and in control group

\begin{tabular}{|c|c|c|c|c|}
\hline & $\begin{array}{c}\text { PAH group } \\
n=40\end{array}$ & $\begin{array}{c}\text { Control group } \\
n=40\end{array}$ & P value & OR(95\% CI) \\
\hline \multicolumn{5}{|c|}{ MDR G2677T genotype } \\
\hline GG & 10 & 11 & - & - \\
\hline GT & 24 & 22 & 0.79 & $0.912(0.53-1.54)$ \\
\hline TT & 6 & 7 & 1 & $1.032(0.49-2.16)$ \\
\hline GT+TT & 30 & 29 & 0.80 & $1.136(0.53-2.40)$ \\
\hline \multicolumn{5}{|c|}{ Allele frequency } \\
\hline $\mathrm{G}$ allele & 44 & 44 & \multirow{2}{*}{1.12} & \multirow{2}{*}{$1.000(0.53-1.86)$} \\
\hline T allele & 36 & 36 & & \\
\hline \multicolumn{5}{|c|}{ MDR C1236T genotype } \\
\hline $\mathrm{CC}$ & 11 & 6 & - & - \\
\hline $\mathrm{CT}$ & 22 & 20 & 0.56 & $1.235(0.78-1.94)$ \\
\hline TT & 7 & 14 & 0.10 & $1.941(0.96-3.90)$ \\
\hline $\mathrm{CT}+\mathrm{TT}$ & 29 & 34 & 0.27 & $1.833(0.75-4.47)$ \\
\hline \multicolumn{5}{|c|}{ Allele frequency } \\
\hline $\mathrm{C}$ & 44 & 32 & \multirow{2}{*}{0.08} & \multirow{2}{*}{$1.375(0.98-1.92)$} \\
\hline $\mathrm{T}$ & 36 & 48 & & \\
\hline \multicolumn{5}{|c|}{ MDR C3435T genotype } \\
\hline $\mathrm{CC}$ & 12 & 8 & - & - \\
\hline $\mathrm{CT}$ & 21 & 17 & 0.78 & $1.086(0.68-1.71)$ \\
\hline TT & 7 & 15 & 0.11 & $1.886(0.92-3.83)$ \\
\hline $\mathrm{CT}+\mathrm{TT}$ & 28 & 32 & 0.43 & $1.714(0.61-4.79)$ \\
\hline \multicolumn{5}{|c|}{ Allele frequency } \\
\hline $\mathrm{C}$ & 45 & 33 & \multirow{2}{*}{0.08} & \multirow{2}{*}{$1.831(0.97-3.42)$} \\
\hline $\mathrm{T}$ & 35 & 47 & & \\
\hline
\end{tabular}

MDR1 SNPs genotypes and alleles in PAH subgroups: worsening versus non-worsening

In terms of G2677T, C3435T and C1236T SNPs, we found no differences in the frequency distribution of genotypes and alleles between PAH children with clinical worsening and non-worsening (Table 3). Also, when the synergic effects of two or three SNPs in different combination were assessed, we found no significant differences in these two groups.

\section{Discussions}

Although the progress in understanding of PAH pathophysiology has increased significantly in recent years, the prognosis of PAH remains unfavourable. Efforts are being made to investi- gate new genetic and molecular mechanisms involved in the pathogenesis of this progressively devastating disease.

MDR1 gene polymorphism, associated with the decrease of synthesis and alteration of P-gp function, has been associated with many pathologies in which it modifies the pharmacokinetics of therapeutic agents $(26,28,29)$. Pulmonary vasodilator therapy (endothelin receptor antagonists and phosphodiesterase type 5 inhibitors) does not act as an exogenous inducer of P-gp expression, which is why MDR1 polymorphism could not be associated with the efficiency of specific PAH treatment.

On the other hand, P-gp facilitates transmembrane intracellular transport of various toxins, de- 
Table 3. Distribution of different genotypes and allele distribution in the PAH children groups (worsening and nonworsening)

\begin{tabular}{|c|c|c|c|c|}
\hline & $\begin{array}{c}\text { worsening PAH } \\
(\mathrm{n}=12)\end{array}$ & $\begin{array}{c}\text { Nonworsening PAH } \\
(\mathrm{n}=28)\end{array}$ & P value & OR $(95 \% \mathrm{CI})$ \\
\hline \multicolumn{5}{|c|}{ MDR G2677T genotype } \\
\hline GG & 2 & 8 & - & - \\
\hline GT & 7 & 17 & 0.69 & $0.685(0.17-2.74)$ \\
\hline TT & 3 & 3 & 0.29 & $0.40(0.09-1.75)$ \\
\hline GT+TT & 10 & 20 & 0.69 & $0.500(0.08-2.80)$ \\
\hline \multicolumn{5}{|c|}{ Allele frequency } \\
\hline G allele & 11 & 33 & \multirow{2}{*}{0.33} & \multirow{2}{*}{$0.589(0.22-1.54)$} \\
\hline T allele & 13 & 23 & & \\
\hline \multicolumn{5}{|c|}{ MDR C1236T genotype } \\
\hline $\mathrm{CC}$ & 2 & 8 & - & - \\
\hline $\mathrm{CT}$ & 7 & 16 & 0.68 & $0.657(0.16-2.62)$ \\
\hline TT & 3 & 4 & 0.59 & $0.466(0.10-2.10)$ \\
\hline $\mathrm{CT}+\mathrm{TT}$ & 10 & 20 & 0.69 & $0.600(0.15-2.29)$ \\
\hline \multicolumn{5}{|c|}{ Allele frequency } \\
\hline $\mathrm{C}$ & 11 & 32 & \multirow{2}{*}{0.81} & \multirow{2}{*}{$1.088(0.55-2.12)$} \\
\hline $\mathrm{T}$ & 13 & 24 & & \\
\hline \multicolumn{5}{|c|}{ MDR C3435T genotype } \\
\hline $\mathrm{CC}$ & 4 & 8 & - & - \\
\hline $\mathrm{CT}$ & 5 & 16 & 0.69 & $1.40(0.46-4.23)$ \\
\hline TT & 3 & 4 & 1 & $0.777(0.24-2.51)$ \\
\hline $\mathrm{CT}+\mathrm{TT}$ & 8 & 20 & 0.76 & $1.167(0.43-3.14)$ \\
\hline \multicolumn{5}{|c|}{ Allele frequency } \\
\hline $\mathrm{C}$ & 13 & 32 & \multirow{2}{*}{0.80} & \multirow{2}{*}{$0.916(0.47-1.79)$} \\
\hline $\mathrm{T}$ & 11 & 24 & & \\
\hline
\end{tabular}

creasing the intracellular concentration of toxic compounds (16). The role of inflammation and oxidative stress in PAH pathogenesis is supported by many studies (3-5, 30-32). Cytokines, growth factors and shear stress represent endogenous activators of NADPH (nicotinamide adenine dinucleotide phosphate oxidase), which is a molecular complex that generates ROS (2). MDR1 polymorphism, associated with decreased P-gp expression, may be involved in the pathogenesis and progression of PAH by affecting cellular protection against deleterious action of ROS (23).

The C1236T, G2677T and C3435T polymorphisms are the most studied single nucleo- tide MDR1 polymorphisms, previous investigations demonstrating the association of MDR1 polymorphism with many diseases $(17,23,29$, 33-37). Manduz $\mathrm{S}$ et al, starting from the idea that MDR1 polymorphism plays a role in the inflammatory process and in the protection against oxidative stress, suggested that $\mathrm{T}$ alleles of the MDR1 C3435T gene are associated with abdominal aortic aneurysm (17). Wartenberg M. et al have associated the risk of spheroidal prostate cancer with the intrinsic decrease in P-gp expression by ROS (29). Ma L. et al concluded that MDR1 C1236T polymorphism may contribute to the susceptibility to chronic myeloid leukemia 
(36). Yamamoto-Furusho J.K. evaluated patients with bowel inflammatory disease and found that MDR1 expression decreased significantly in patients with acute ulcerative colitis compared to patients with inactive disease or patients in the control group (38). Wang L.H. et al, reporting the results of a meta-analysis, suggested that MDR C3435T and G2677A polymorphisms are associated with the risk of cancer, suggesting that different cytokines and chemokines involved in inflammation appear to be P-gp substrates, a potential cause of carcinogenesis (23). The importance of $\mathrm{ABC}$ transporters at tissue level has been studied especially in pulmonary neoplastic pathology $(16,39-41)$. Dogan et al. suggested that MDR1 C3435T polymorphism may play a role in the occurance of chronic obstructive pulmonary disease through an inflamatory mechanism (40). Martinelli M. has not established an association between MDR1 polymorphisms and idiopathic pulmonary fibrosis (41).

The current study did not identify any association between MDR1 C1236T, MDR1 G2677T and MDR1 C3435T polymorphisms (separately or in combination) and PAH in child population. Furthermore, these three MDR1 gene single nucleotide polymorphisms could not be correlated with the clinical worsening of pediatric $\mathrm{PAH}$ patients.

Pediatric PAH is a relative rare condition. Study data from the Netherlands have revealed a point prevalence of 4.4 for IPAH and 15.6 for CHD-PAH cases per million children (42). Considering that almost two-thirds of the Romanian pediatric PAH cases (40 out of 64) are treated and followed-up in the Centre where the present study was carried out, and the Romanian child population is up to 4.4 million, we estimate that there is a reliable number of patients enrolled in this study.

This is the first study to evaluate the role of MDR1 polymorphism in the clinical course of pediatric PAH patients. Lack of association be- tween MDR1 SNPs and PAH may be explained by the existence of numerous MDR1 polymorphisms (about 50) that could be analyzed. Future genetic studies that evaluate inflammation and oxidative stress in $\mathrm{PAH}$ pathogenesis are needed to elucidate the genetic and molecular mechanisms involved in PAH progression. A better understanding of these mechanisms would lead to management optimization of patients with PAH and to the development of new therapeutic strategies.

\section{Conclusion}

MDR1 C1236T, MDR1 G2677T and MDR1 C3435T polymorphisms could not be correlated with the clinical evolution of pediatric $\mathrm{PAH}$ patients in our study.

\section{Conflict of interest}

The authors declare that there is no conflict of interest.

\section{References}

1. Bazan IS, Fares WH. Pulmonary hypertension: diagnosis and therapeutic challenges. Ther Clin Risk Manag. 2015 Aug 17;11:1221-33.

2. Crosswhite P, Sun Z. Nitric Oxide, oxidative stress and inflammation in pulmonary arterial hypertension. J Hipertens. 2010; 28(2):201-12. DOI: 10.1097/ HJH.0b013e328332bcdb

3. Ghasemzadeh N, Patel RS, Eapen DJ, Veledar E, Kassem HA, Manocha P, et al. Oxidative stress is associated with increased pulmonary artery systolic pressure in humans. Hypertension. 2014 Jun;63(6):1270-5. DOI: 10.1161/HYPERTENSIONAHA.113.02360

4. Sanders KA, Hoidal JR. The NOX on pulmonary hypertension. Circ Res. 2007; 101:224-6. DOI: 10.1161/ CIRCRESAHA.107.158246

5. Fulton DJR, Li X, Bordan Zs, Haigh S, Bentley A, Chen F, et al. Reactive Oxygen and Nitrogen Species in the Development of Pulmonary Hypertension. Antioxidants (Basel). 2017; 6(3):54. DOI: 10.3390/antiox 6030054 
6. McLaughlin VV, Gaine SP, Haward LS, Leuchte HH, Mathier MA, Mehta S, et al. Treatment goals of pulmonary hypertension. JACC. 2013; 24:62(25 Suppl):D73-81.

7. Humbert M, Lau EMT, Montani D, Jais X, Sitbon O, Simonneau G. Advances in therapeutic interventions for patients with pulmonary arterial hypertension. Circulation. 2014; 130:2189-208. DOI: 10.1161/CIRCULATIONAHA.114.006974

8. Fares WH, Trow TK. Targeted approaches to the treatment of pulmonary hypertension. Ther Adv Respir Dis. 2012; 6:147-59. DOI: $10.1177 / 1753465812441849$

9. Austin ED, Loyd JE. The genetics of pulmonary arterial hypertension. Circ Res. 2014; 115(1):189-202. DOI: 10.1161/CIRCRESAHA.115.303404

10. Muntean I, Togănel R, Benedek T. Genetics of congenital heart disease: past and present. Biochem Genet. 2017; 55(2):105-23. DOI: 10.1007/s10528-016-9780-7

11. Girerd B, Montani D, Coulet F, Sztrymf B, Yaici A, Jaïs $\mathrm{X}$, et al. Clinical outcomes of pulmonary arterial hypertension in patients carrying an ACVRL1 (ALK1) mutation. Am J Respir Crit Care Med. 2010; 181(8):851-61. DOI: $10.1164 / \mathrm{rccm} .200908-12840 \mathrm{C}$

12. Girerd B, Weatherald J, Montani D, Humbert M. Heritable pulmonary hypertension: from bench to bedside. Eur Respir Rev. 2017;26(145):170037. DOI: 10.1183/16000617.0037-2017

13. Pânzaru M, Rusu C, Voloşciuc M, Braha E, Butnariu L, Gramescu M, et al. Benefits of cytogenetic testing in diagnosis of plurimalformative syndromes with congenital heart defects. Rev Romana Med Lab. 2012;20(3):265-72.

14. Togănel R, Muntean I, Duicu C, Făgărăşan A, Gozar L, Bănescu C. The role of eNOS and AGT gene polymorphisms in secondary pulmonary arterial hypertension in Romanian children with congenital heart disease. Rev Romana Med Lab. 2013; 21(3):267-74. DOI: 10.2478/ rrlm-2013-0031

15. Hoffmeyer S, Burk O, von Richter O, Arnold HP, Brockmöller J, Johne A et al. Functional polymorphisms of the human multidrug-resistance gene: multiple sequence variations and correlation of one allele with P-glycoprotein expression and activity in vivo. Proc Natl Acad Sci U S A. 2000; 97(7):3473-8. DOI: 10.1073/pnas.97.7.3473

16. van der Deen M, de Vries EG, Timens W, Scheper RJ, Timmer-Bosscha H, Postma DS. ATP-binding cassette
(ABC) transporters in normal and pathological lung. Respir Res. 2005; 6:59. DOI: 10.1186/1465-9921-6-59

17. Manduz Ş, Katrancioğlu N, Karahan O, Yılmaz MB, Özdemir Ö, Berkan Ö. Associations between common $3435 \mathrm{C}>\mathrm{T}$ variants of the multi-drug resistance [MDR$1(\mathrm{ABCB} 1)]$ gene and abdominal aortic aneurysm: a pilot study. Turkish Journal of Thoracic and Cardiovascular Surgery. 2011; 19(2):177-81. DOI: 10.5606/tgkdc. dergisi.2011.008

18. Batetta B, Dessì S, Putzolu M, Sanna F, Spano O, Mulas MF et al. MDR1 gene expression in normal and atherosclerotic human arteries (1). J Vasc Res. 1999; 36:261-71. DOI: 10.1159/000025654

19. Dombrowski SM, Desai SY, Marroni M, Cucullo L, Goodrich K, Bingaman W, et al. Overexpression of multiple drug resistance genes in endothelial cells from patients with refractory epilepsy. Epilepsia. 2001; 42:1501-6. DOI: 10.1046/j.1528-1157.2001.12301.x

20. Bebek N, Çine N, Öner GÖ, Eşkazan E, Özbek U. Genotype and Allele frequencies of MDR-1 C3435T polymorphism in Turkish population. J Neurol Sci. 2005; 22(37):261-6.

21. Ji-Ye Y, Qiong H, Youyun Y, Jian-Ting Z, Mei-Zuo $Z$, Hong-Hao Z, et al. Characterization and analyses of multidrug resistance-associated protein 1 (MRP1/ $\mathrm{ABCC} 1)$ polymorphisms in Chinese population. Pharmacogenet Genomics. 2009; 19(3):206-16. DOI: 10.1097/FPC.0b013e328323f680

22. Tang K, Ngoi SM, Gwee PC, Chua JM, Lee EJ, Chong SS et al. Distinct haplotype profiles and strong linkage disequilibriumat the MDR1 multidrug transporter gene locus in three ethnic Asian populations. Pharmacogenetics. 2002; 12:437-50. DOI: 10.1097/00008571200208000-00004

23. Wang LH, Song YB, Zheng WL, Jiang L, Wen-Li. The association between polymorphisms in the MDR1 gene and risk of cancer: a systematic review and pooled analysis of 52 case-control studies. Cancer Cell Int. 2013; 13:46. DOI: $10.1186 / 1475-2867-13-46$

24. Galie N, Humbert M, Vachiery JL, Gibbs S, Lang I, Torbicki A, et al. 2015 ESC/ERS Guidelines for the diagnosis and treatment of pulmonary hypertension. Eur Heart J. 2016;37(1):67-119 DOI: 10.1093/eurheartj/ ehv317

25. American Thoracic Society. American Thoracic Society statement: guidelines for the six-minute walk test. Am J Respir Crit Care Med. 2002; 166:111-7. DOI: 
10.1164/ajrccm.166.1.at1102

26. Dong L, Luo R, Tong Y, Cai X, Mao M, Yu D. Lack of association between ABCB1 gene polymorphisms and pharmacoresistant epilepsy: an analysis in a western Chinese pediatric population. Brain Res. 2011; 1391:114-24. DOI: 10.1016/j.brainres.2011.03.028

27. Todoran Butila A, Sin A, Racoş Szabo E, Micheu C, Moldovan VG, Voidazan S et al. ABCB1 gene polymorphisms is not associated with drug-resistant epilepsy in Romanian children. Rev Romana Med Lab. 2015; 23(4):469-82. DOI: $10.1515 / \mathrm{rrlm}-2015-0037$

28. Wolking S, Schaeffeler E, Lerche H, Schwab M, Nies AT. Impact of genetic polymorphisms of $\mathrm{ABCB} 1$ (MDR1, G-Glycoprotein) on drug disposition and potential clinical implications: update of the literature. Clin Pharmacokinet. 2015; 54(7):709-35. DOI: 10.1007/s40262-015-0267-1

29. Wartenberg M, Ling FC, Schallenberg M, Bäumer AT, Petrat K, Hescheler J et al. Down-regulation of intrinsic P-glycoprotein expression in multicellular prostate tumor spheroids by reactive oxygen species. J Biol Chem. 2001; 276(20):17420-8. DOI: 10.1074/jbc. M100141200

30. Dorfmüller P, Perros F, Balabanian K, Humbert M. Inflammation in pulmonary arterial hypertension. Eur Respir J. 2003; 22:358-63. DOI: 10.1183/09031936.03.00038903

31. Tuder RM, Groves B, Badesch DB, Voelkel NF. Exuberant endothelial cell growth and elements of inflammation are present in plexiform lesions of pulmonary hypertension. Am J Pathol. 1994; 144:275-85.

32. Sakamaki F, Kyotani S, Nagaya N, Nagato Sato N, Oya $\mathrm{H}$, Satoh T, et al. Increased plasma P-selectin and decreased thrombomodulin in pulmonary arterial hypertension were improved by continuous prostacyclin therapy. Circulation. 2000; 102:2720-5. DOI: 10.1161/01. CIR.102.22.2720

33. Sapmaz A, Ozen Karatayli SC, Dağli U, Kiliç ZM, Törüner M, Celik Y et al. Effects of polymorphism in G2677T/A triallelic region of MDR1 gene in Turkish patients with inflammatory bowel disease. Turk J Gastroenterol. 2008; 19:168-73.
34. Kedmi M, Maayan S, Cohen SB, Hauzi M, Rund D. MDR1 and CYP3A4 polymorphisms are associated with HIV seropositivity in Israeli patients but do not influence the course of HIV disease. AIDS Patient Care STDS. 2007; 21:653-8. DOI: 10.1089/apc.2006.0148

35. Elghannam DM, Ibrahim L, Ebrahim MA, Azmy E, Hakem H. Association of MDR1 gene polymorphism (G2677T) with imatinib response in Egyptian chronic myeloid leukemia patients. Hematology. 2014;19:1238. DOI: $10.1179 / 1607845413$ Y.0000000102

36. Ma L, Liu H, Ruan L, Yang X, Yang H, Feng Y. Multidrug resistance gene $1 \mathrm{C} 123 \mathrm{~T}$ polymorphism and susceptibility to leukemia: a meta-analysis. Biomed Rep. 2015; 3(1):83-7. DOI: 10.3892/br.2014.387

37. Sabin O, Bocşan IC, Trifa A, Major ZZ, Heghes SC, Brusturean Bota E, et al. Correlation between ABCB1 gene polymorphisms, antiepileptic drug concentrations and treatment response. Rev Romana Med Lab. 2018 (ahead of print). DOI:10.2478/rrlm-2018-0012

38. Yamamoto-Furusho JK, Villeda-Ramirez MA, Fonseca-Camarillo G, Sanchez-Munoz F, Dominiquez-Lopez A, Barreto-Zuniga $R$, et al. High gene expression of MDR1 (ABCB1) is associated with medical treatment response and long-term remission in patients with ulcerative colitis. Inflam Bowel Dis. 2010; 16:541-2. DOI: 10.1002/ibd.21016

39. Milojkovic M, Milacic N, Radovic J, Ljubisavljevic S. MDR1 gene polymorphisms and p-glycoprotein expression in respiratory diseases. Biomed Pap Med Fac Univ Palacky Olomouc Czech Repub. 2015; 159(3):341-6. DOI: $10.5507 /$ bp. 2014.032

40. Dogan OT, Katrancioglu N, Karahan O, Sanli GC, Zorlu A, Manduz S. Frequency of the MDR-1 C $>$ T gene polymorphism in patients with COPD. Clinics (Sao Paulo). 2010; 65:1115-7.

41. Martinelli M, Scapoli L, Pacilli AMG, Carbonara P, Girardi A, Mattei G, et al. Human Multidrug Resistance 1 gene polymorphisms and idiopathic pulmonary fibrosis. J Res Med Sci. 2015; 20(1):93-6.

42. Takatsuki S, Ivy DD. Current Challenges in Pediatric Pulmonary Hypertension. Semin Respir Crit Care Med. 2013; 34(5):627-44. DOI: 10.1055/s-0033-1356461 